\title{
Yeasts from Canastra cheese production process: Isolation and evaluation of their potential for cheese whey fermentation
}

\author{
Rafaela Pereira Andrade a , Carolina Naves Melo a , Zlatina Genisheva b, \\ Rosane Freitas Schwan ${ }^{\text {a }}$, Whasley Ferreira Duarte ${ }^{\mathrm{a}, *}$ \\ a Department of Biology, University of Lavras (UFLA) - Campus Universitário, CEP 37.200-000 Lavras, MG, Brazil \\ ${ }^{\mathrm{b}}$ CEB - Centre of Biological Engineering, University of Minho, 4710-057, Braga, Portugal
}

\section{A R T I C L E I N F O}

\section{Article history:}

Received 22 September 2016

Received in revised form 21 November 2016

Accepted 27 November 2016

Available online 30 November 2016

\section{Keywords:}

Cheese yeasts

Lactose fermentation

Ethanol

Aromatic compounds

MALDI TOF

\begin{abstract}
A B S T R A C T
Canastra cheese is a cheese with geographical indication recognized by the Brazilian National Institute of Industrial Protection under number IG201002. It is produced in seven municipalities in the state of Minas Gerais in a region called Serra da Canastra. In this work, samples of milk, "pingo" (natural starter), whey and Canastra cheese were collected on a farm in Medeiros-MG/Brazil to evaluate the yeast microbiota and select yeasts for whey fermentation to produce ethanol and volatile aromatic compounds of relevance in the production of cheese. Thirtynine isolates capable of fermenting lactose in a synthetic medium were identified by MALDI-TOF as Kluyveromyces lactis (29), Torulaspora delbrueckii (7) and Candida intermedia (3). Eleven isolates of K. lactis and three of $T$. delbrueckii efficiently fermented lactose until 4th day, and due to this reason were selected for cheese whey fermentation with Brix 12, 14 and 18. Generally, the isolates T. delbrueckii B14, B35, and B20 and K. lactis B10 were the most effective regardless of the initial Brix value. The identification of these four isolates by MALDI TOF was confirmed by sequencing of the ITS region. In the fermentation of cheese whey 14 Brix, $T$. delbrueckii B14 and B35, respectively yielded $24.06 \mathrm{~g} / \mathrm{L}$ and $16.45 \mathrm{~g} / \mathrm{L}$ of ethanol, while K. lactis B10 was more efficient in the consumption of lactose. In sequential culture with $K$. lactis B10 inoculated $48 \mathrm{~h}$ after T. delbrueckii B14, 97.82\% of the total sugars were consumed resulting in the production of $19.81 \mathrm{~g} / \mathrm{L}$ ethanol and 39 aromatic volatile compounds. The most abundant compounds were 3-methyl-1-butanol, octanoic acid and ethyl decanoate, which are reported as important for the aroma and flavor of cheeses. Based in our results, B10 isolate inoculated $48 \mathrm{~h}$ after B14 isolate is a promising yeast inoculum to be used for fermentation of dairy substrates.
\end{abstract}

(c) 2016 Elsevier Ltd. All rights reserved.

\section{Introduction}

Canasta cheese is a type of white cheese, produced in Serra da Canastra region, specifically in seven municipalities of Minas Gerais state - Brazil. The geographical indication has been recognized by the National Institute of Industrial Protection (INPI) in 2011 under number IG201002. The climate, altitude, native pasture and Canastra waters (Resende et al., 2011) allow this cheese to have a unique flavor being considered dense and full-bodied. This cheese is produced from cow raw milk inoculated with the commercial rennet and "pingo". The "pingo" is a type of natural starter obtained from the cheese whey released in cheese production on the previous day. Its microbiota consists of bacteria, particularly lactic acid bacteria, and yeasts (Lima, Lima, Cerqueira, Ferreira, \& Rosa, 2009; Nóbrega et al., 2008). Among the yeast species found in the "pingo" and Canastra cheese, Borelli, Ferreira, Lacerda, Franco, and Rosa (2006) reported as the most frequent

\footnotetext{
* Corresponding author.

E-mail address: whasleyduarte@dbi.ufla.br (W.F. Duarte).
}

Kodamaea ohmeri, Debaryomyces hansenii, Torulaposra delbrueckii and Kluyveromyces lactis.

Several studies have reported the presence of yeast in milk and its derivatives (Borelli et al., 2006; Lopandic, Zelger, Bánszky, Eliskases-Lechner, \& Prillinger, 2006), as they have in their constitution proteins, lipids and organic acids, which favor the growth of various species of yeast (Lopandic et al., 2006). Due to their characteristics, such as production lipolytic and proteolytic activities, assimilation and fermentation of lactose, tolerance of high salt concentrations, low $\mathrm{pH}$, low water activity and low temperatures (Jakobsen \& Narvhus, 1996; Lopandic et al., 2006), yeasts isolated from the cheese production process have been studied for their biotechnological potential such as the production of enzymes (Borelli et al., 2006), flavors (Chen et al., 2012) and cheese ripening (Gardini et al., 2006).

The Brazilian production of cheese whey in 2010 Brazil was estimated by Alves et al. (2014) in 8 billion litters. As cheese whey has about $55 \%$ of the nutrients contained in milk, it is an interesting source of nutrients for the use in microorganism growth. However, this by-product also has high pollution potential due to its high BOD (Biological Oxygen Demand) and lactose content. Over the years, fermentative processes 
have been considered as an alternative to the use of this by-product, being lactose utilized by various microorganisms such as yeasts and bacteria in order to generate added value products (Becerra, Cerdán, \& González-Siso, 2015) such as ethanol (Ozmihci \& Kargi, 2008), butanol (Becerra et al., 2015), bacteriocins (Schirru et al., 2014), hydrogen and methane (Cota-Navarro, Carrillo-Reyes, Davila-Vazquez, AlatristeMondragón, \& Razo-Flores, 2011) and $\beta$-galactosidase (Rech, Cassini, Secchi, \& Ayub, 1999). Among the used microorganisms, K. lactis has been the most often studied, mainly in the fermentation of cheese whey to produce ethanol (Christensen, Kádár, Oleskowicz-Popiel, \& Thomsen, 2011) and ethyl acetate (Urit, Löser, Wunderlich, \& Bley, 2011).

Recently, the Matrix Assisted Laser Desorption Ionization Time of Flight Mass Spectrometry (MALDI TOF MS) has been used to identify yeasts in fermentative processes for the production of cachaça (Amorim, Schwan, \& Duarte, 2016) ethanol, baking, wine and beer (Moothoo-Padayachie, Kandappa, Krishna, Maier, \& Govender, 2013; Spitaels et al., 2014). This technique is characterized by its low cost, time consumption and reliability. Although there are works reporting the use of this technique for yeast identification in aforementioned fermentative processes, to the best of our knowledge, there are no published works on the use MALDI TOF MS related to yeasts identification in cheese production process.

Despite reports on the literature regarding the isolation and identification of microorganisms from cheese production process and the use of yeast such as K. lactis for cheese whey fermentation, in this work, we report for the first time the use of yeasts isolated from the Canastra cheese production process in a mixed inoculum to ferment cheese whey and produce ethanol and volatile aromatic compounds. Therefore, the objectives of this study were to isolate and identify yeasts from milk, pingo, Canastra cheese and its whey, and also to evaluate the potential of these yeasts in single and mixed culture for the fermentation of cheese whey sugars to produce ethanol and volatile aromatic compounds.

\section{Material and methods}

\subsection{Sampling and yeasts isolation}

Samples of milk, pingo, Canastra cheese and cheese whey were collected in a farm located in the Serra da Canastra region, city of Medeiros - MG/Brazil. The yeast isolation was performed according to the methodology described by Borelli et al. (2006) using YPD medium. After incubation at $28{ }^{\circ} \mathrm{C}$ for $48 \mathrm{~h}$, the number of colony forming units (CFU) was recorded and the colonies were properly characterized following the protocol described by Kurtzman, Fell, Boekhout, and Robert (2011). The morphological characteristics of each colony morphotype were recorded and a number of colonies corresponding to the squareroot of the number of colonies of each type were re-streaked and purified on YPD. The purified and characterized cellular morphotypes were stored in glycerol $40 \%$ at $-20{ }^{\circ} \mathrm{C}$ for use in later stages of the work.

\subsection{Lactose fermentation in synthetic medium}

The isolates obtained from milk, pingo, Canastra cheese and cheese whey samples were evaluated for their lactose fermentation capacity according to the methodology described by Kurtzman et al. (2011). Briefly, the fermentation basal medium composed by $4.5 \mathrm{~g} / \mathrm{L}$ of yeast extract and $7.5 \mathrm{~g} / \mathrm{L}$ of peptone was added of bromothymol blue at a final concentration of $25.6 \mathrm{mg} / \mathrm{L}$ of medium. Two milliliters of basal medium was added to a tube containing inverted Durham tube and sterilized for $15 \mathrm{~min}$ at $121^{\circ} \mathrm{C}$. After autoclaving, $1 \mathrm{~mL}$ of filter sterilized lactose solution was added to a final concentration of $2 \%(w / v)$. The fermentations were carried out in triplicate.

\subsection{Yeasts identification by MALDI TOF}

The yeast isolates which fermented lactose in synthetic medium were subjected to MALDI TOF analysis for the identification according to the methodology described by Amorim et al. (2016). All extractions were performed in triplicate and each repetition was spotted three times on the MALDI stainless steel target. The identification of yeast was performed using Biotyper library. According to the manufacturer, score values should be above 1.99 for a reliable identification to the species level. For cluster analysis, the raw spectra were converted into text files using FlexAnalysis software (version 3.4) containing the list of peaks $(\mathrm{m} / \mathrm{z})$ and their intensities. Spectra were then attenuated, the base line was subtracted and the signal intensities were normalized using the mMass software version 5.5 (Niedermeyer \& Strohalm, 2012). After treatment of the raw spectra, average spectra were generated and peak picking was performed using a signal-to-noise ratio threshold of 5 . The peaks were aligned by generating a consensus peak list using SPECLUST (Alm et al., 2006), available at http://co.bmc. lu.se/speclust/cluster.pl. This consensus peak list was then used for the cluster analysis in XLstat 2014.5 software (Addinsoft's, New York, NY) using Pearson similarity and Unweighted Pair-Group Average (UPGA).

\subsection{Cheese whey fermentation}

The yeasts isolates which fermented lactose in synthetic medium until the fourth day were evaluated for their ability to ferment cheese whey with different Brix, 12, 14 and 18 . The 12 Brix cheese whey was obtained from the dilution of 14 Brix cheese whey with sterile distilled water, while the 18 Brix cheese whey was obtained by evaporation of 14 Brix cheese whey. Before yeasts inoculation the cheese whey was pasteurized by direct steam in an autoclave for $7 \mathrm{~min}$. The isolates were reactivated in liquid YPD during $24 \mathrm{~h} / 28^{\circ} \mathrm{C}$. After, the biomass was centrifuged at $25^{\circ} \mathrm{C} / 7000 \mathrm{rpm}$ for $10 \mathrm{~min}$ to remove the supernatant and washed 2 times with sterile $0.1 \%$ peptone water. All isolates were inoculated with a population of $10^{7}$ cells $/ \mathrm{mL}$. The Brix was measured every 12 h until stabilization.

\subsection{Confirmation of the yeast identity by sequencing the ITS region}

The four yeast isolates that showed better results in cheese whey fermentation under different Brix were subjected to analysis of ITS region to confirm the identity obtained in MALDI TOF analysis. The isolates were reactivated in YPD for $24 \mathrm{~h} / 28^{\circ} \mathrm{C}$ and then transferred to a plate containing solid YPD for $24 \mathrm{~h} / 28{ }^{\circ} \mathrm{C}$. A colony was suspended in $1 \mathrm{~mL}$ sterile Milli-Q water and centrifuged at $12000 \mathrm{rpm}$ for $1 \mathrm{~min}$ and the supernatant was removed. The precipitate was used for DNA extraction using a QIA amp DNA Kit (Qiagen, Hilden, Germany) according to the manufacturer's instructions. DNA purification was performed on QIA quick PCR Purification Kit (Qiagen). The PCR analysis was performed as described by Esteve-Zarzoso, Belloch, Uruburu, and Querol (1999) and Naumova, Ivannikova, and Naumov (2005) using the primers ITS1 (5'-TCCGTAGGTGAACCTGCGG-3') and ITS4 (5'-TCCTCCGCTTATTGA TATGC- $\left.3^{\prime}\right)$. The sequencing was performed in the Síntese Biotecnologia Company (Belo Horizonte - MG/Brazil). The obtained sequences were compared with those available in Genbank for subsequent yeast identification. The identification obtained from the sequencing was compared with the identification from MALDI TOF for confirming the identity of the studied yeasts isolates.

2.6. Assessment of the yeasts potential to produce ethanol and volatile aromatic compounds

\subsubsection{Fermentation for ethanol production using single species inocula}

The most efficient yeasts in the fermentation of cheese whey with different Brix were first evaluated as single species inocula for lactose, galactose and glucose consumption and ethanol production. For this 
evaluation, experiments were performed with pure cultures of the previously selected yeasts inoculated $\left(10^{7}\right.$ cells $\left./ \mathrm{mL}\right)$ in 14 Brix cheese whey. The inocula multiplication, cheese whey pasteurization, inoculation procedure and fermentation conditions were the same as described in Section 2.4.

2.6.2. Fermentation for ethanol and aromatic volatile compounds production using mixed inocula

After the evaluation of yeast fermentative potential in single cultures, those isolates with best results were selected for use in co-cultivation or inoculated sequentially. In co-cultures, two yeasts were inoculated together at the beginning of fermentation, while in the sequential inoculation, one yeast species was inoculated at the beginning of the fermentation and the second species after $48 \mathrm{~h}$ of fermentation with the first one. In both cases the used inoculation ratio was 1:1.

After a first fermentation where the mixed inoculum with the highest consumption of glucose, galactose, and lactose and ethanol production was selected, a second fermentation with $1 \mathrm{~L}$ of cheese whey was performed. All the fermentations were conducted at $30^{\circ} \mathrm{C}$ with the both yeasts of mixed inocula being inoculated in populations of $10^{7}$ cells $/ \mathrm{mL}$ in 14 Brix cheese whey. In both experiments, the kinetic parameter ethanol yield $\left(\mathrm{Y}_{\mathrm{p} / \mathrm{s}}\right)$, sugars conversion into ethanol efficiency $(E f)$, the total sugar conversion (Conv.) and ethanol productivity $\left(\mathrm{Q}_{p}\right)$ were calculated as described by Duarte et al. (2010a) and Oliveira, Rosa, Morgano, and Serra (2004).

$$
\begin{aligned}
{\left[\mathrm{Y}_{\mathrm{p} / \mathrm{s}}\right.} & \left.=\left(\mathrm{P}_{f}-\mathrm{P}_{i}\right) /\left(\mathrm{S}_{i}-\mathrm{S}_{f}\right)\right] ;\left[\mathrm{Q}_{\mathrm{p}}=\left(\mathrm{P}_{f}-\mathrm{P}_{i}\right) / \mathrm{t}_{f}\right] ; \mathrm{Ef} \\
& =\left[\left(\mathrm{Y}_{\mathrm{p} / \mathrm{s}} * 100\right) / 0.51\right] ; \operatorname{Conv}=\left[\left(\mathrm{S}_{i}\right) /\left(\mathrm{S}_{i}-\mathrm{S}_{f}\right) * 100\right]
\end{aligned}
$$

where $P_{i}$ is the initial concentration of ethanol, $P_{f}$ is the ethanol concentration at the of fermentation, $S_{i}$ is initial substrate concentration, $S_{\mathrm{f}}$ is substrate concentration at the end of fermentation.

Ethanol and sugars were analyzed by HPLC and volatile aromatic compounds by GC-MS. All fermentations were carried out in triplicate.

\subsection{Liquid chromatography analysis}

HPLC analysis was performed using a Shimadzu chromatograph, (Shimadzu Corp., Japan) equipped with a refractive index detector (RID-10A) and Supelcogel 8H (Supelco, Bellefonte, PA, USA) column $\left(7.8 \mathrm{~mm} \times 30 \mathrm{~cm}\right.$ ) operated at $30^{\circ} \mathrm{C}$. The elution was performed with $5 \mathrm{mM}$ sulfuric acid at a flow rate of $0.5 \mathrm{~mL} / \mathrm{min}$. The identification of compounds was performed by comparing the retention times of peaks in samples with those of pure standard injected under the same conditions. The quantification was performed by external calibration method (Duarte et al., 2010b).

\subsection{HS-SMPE gas chromatography mass spectrometry}

The solid phase micro extraction (SPME) of volatile compounds was carried out using $5 \mathrm{~mL}$ of fermented cheese whey adding 4-nonanol as an internal standard at a concentration of $125 \mu \mathrm{g} / \mathrm{L}$. Samples were added to $15 \mathrm{~mL}$ vials and the extraction of volatile compounds from the head space (HS) was carried out with a DVB/CAR/PDMS 50/ $30 \mu \mathrm{m}$ fiber (Supelco, Bellefonte, PA, USA) for $25 \mathrm{~min}$ at $60{ }^{\circ} \mathrm{C}$. After extraction, the fiber was kept for $7 \mathrm{~min}$ in the injector for desorption of volatile compounds. The analyses were performed on a GC-MS QP2010SE chromatograph (Shimadzu) equipped with Carbowax column $(30 \mathrm{~m} \times 0.20 \mathrm{~mm}$ id $\times 0.25 \mathrm{um})$ maintained at $50{ }^{\circ} \mathrm{C}$ for $5 \mathrm{~min}$, increased $3{ }^{\circ} \mathrm{C} / \mathrm{min}$ to $190^{\circ} \mathrm{C}$ and maintained for $10 \mathrm{~min}$. The temperature of the injector and detector was $230^{\circ} \mathrm{C}$ and the carrier gas (He) was used in a flow of $1.2 \mathrm{~mL} / \mathrm{min}$. The identification of the compounds was carried out using the NIST library 2011 and pure standards when available. The concentrations were expressed as equivalents of 4nonanol (internal standard) (Amorim et al., 2016).

\subsection{Statistical analysis}

The software SISVAR 5.6 (Lavras, MG, Brazil) was used for analysis of variance (ANOVA) and Scott-Knott test.

\section{Results anddiscussion}

\subsection{Isolation, fermentation of lactose and yeast identification by MALDI TOF}

From the different evaluated samples, in the first step, several colonies morphotypes were characterized (Table 1 ). After this preliminary characterization, a number corresponding to the square root of the total of each morphotype was used for purification and subsequent microscopic characterization. A total of 145 yeast isolates were found, and of these, 83 were from the pingo, 54 from Canastra cheese and 8 from cheese whey. Among the found morphotypes, those designated as $\mathrm{H}$ and I were only found in the pingo; $\mathrm{J}$ and $\mathrm{K}$ were found only in the cheese whey and, E and $G$ were only found in Canastra cheese samples (Table 1). The distribution of the yeast isolates found here is consistent with that reported by Borelli et al. (2006), where a large number of yeasts was observed in samples of cheese and cheese whey, while in the milk this number was lower. This difference in the distribution of yeasts depending on the samples can be attributed to the physicochemical characteristics of milk, pingo, cheese and cheese whey. According to Addis, Fleet, Cox, Kolak, and Leung (2001), temperature, salt concentration, $\mathrm{pH}$ and other microorganisms are factors that interfere or limit the growth of yeasts on cheese. One reason for not detecting yeast in milk samples is the fact the samples were collected right after the milking. Therefore, there was no time for yeast multiplication. Other reasons that we believe have influenced the results are the physical-chemical characteristics of milk and the asepsis in the handling of the milk samples until the beginning of the cheese manufacturing process.

The fermentation of synthetic medium resulted in 39 isolates with the ability to ferment lactose (Table 1). These 39 isolates were subjected to MALDI TOF analysis. According to the cluster analysis (Fig. 1), the isolates were differentiated in three main branches (G1, G2 and G3). Twenty nine isolates identified as $K$. lactis were grouped together in a branch (G1) of the dendrogram. The second branch (G2) was composed by 3 isolates identified as C. intermedia. In the third branch (G3), 7 isolates were grouped together and identified as T. delbrueckii. Fourteen

Table 1

Morphological diversity of yeasts colonies isolated from different samples and their lactose fermentation capacity in synthetic medium.

\begin{tabular}{llllll}
\hline \multirow{2}{*}{ Morphotype } & \multicolumn{2}{l}{ Samples } & $\begin{array}{l}\text { Lactose } \\
\text { fermentation }\end{array}$ \\
\cline { 2 - 5 } & Milk & Pingo & $\begin{array}{l}\text { Cheese } \\
\text { whey }\end{array}$ & $\begin{array}{l}\text { Canastra } \\
\text { cheese }\end{array}$ \\
\hline A & - & 15 & 1 & 7 & 2 \\
B & - & 34 & - & 22 & 25 \\
C & - & 16 & - & 7 & 5 \\
D & - & 14 & 2 & 8 & 6 \\
E & - & - & - & 2 & 0 \\
F & - & 1 & - & 5 & 0 \\
G & - & - & - & 3 & 0 \\
H & - & 1 & - & - & 1 \\
I & - & 2 & - & - & 0 \\
J & - & - & 4 & - & 0 \\
K & - & - & 1 & - & 0 \\
Total & - & 83 & 8 & 54 & 39 \\
\hline
\end{tabular}

The characteristics found in each morphotype were: A, beige, circular, margin entire, smooth, and big; B, beige, circular, smooth, and small.

C, beige, round, smooth, and very small; D, white, irregular, umbonate, dull and small; E, beige, irregular, dull and small.

$\mathrm{F}$, white, irregular, margin lobate, dull and small; $\mathrm{G}$, white, irregular, undulate, and very small; $\mathrm{H}$, white, raised, round, large.

I, white, round, flat, and small; J, beige, round, smooth, with brightness and small; K, beige, round, smooth, with brightness and big.

a The data correspond to the number of selected strains of each purified morphotype. 
isolates showed intense release of $\mathrm{CO}_{2}$ until the 4th day of fermentation and among then, 11 isolates were K. lactis and 3 T. delbrueckii. All identifications were performed using Bruker Biotyper library and the scores ranged from 2.24 to 2.85 for K. lactis, 2.04 to 2.25 for $T$. delbrueckii, and from 2.22 to 2.30 for $C$. intermedia. According to the manufacturer, score values above 1.99 allow reliably identification to the species level. These data reinforce the efficiency and feasibility of the MALDI TOF technique for the identification and grouping of yeast from fermentation processes as reported in some papers such as (Amorim et al., 2016) and (Usbeck, Wilde, Bertrand, Behr, \& Vogel, 2014).

The yeast species identified in this work are often reported by several authors as predominantly associated with milk and milk products (Borelli et al., 2006; Lopandic et al., 2006; Pereira-Dias, Potes, Marinho, Malfeito-Ferreira, \& Loureiro, 2000), including in Canastra cheese, its pingo and whey (Borelli et al., 2006; Nóbrega et al., 2008). As reported in other works (Borelli et al., 2006; Nóbrega et al., 2008), K. lactis is frequently isolated from dairy products such as cheeses, which might be due to its capacity of fermenting lactose. Six of the seven isolates of T. delbrueckii were found in pingo sample, which is in agreement with Borelli et al. (2006), who reported a greater number of this species in pingo samples. The other identified species, $C$. intermedia, has been reported in different types of cheese such as sheep milk cheese by Pereira-Dias et al. (2000) and Gardini et al. (2006), but not reported in the Canastra cheese, although it has already been identified in other cheeses in Minas Gerais/Brazil, as in Serro cheese by Cardoso et al. (2015). This yeast has a variable capacity to ferment lactose, which can probably interfere in its presence or not in substrates rich in lactose. Some yeast species reported by Borelli et al. (2006) were not found in this work, which could be due to the fact that the identification was performed only for a representative group of isolates capable of fermenting lactose.

\subsection{Selection of isolates for cheese whey fermentation}

Eleven isolates of $K$. lactis and 3 isolates of T. delbrueckii that fermented lactose in synthetic medium until the 4th day were used for the fermentation of cheese whey with 12, 14 and 18 Brix (around 120,140 and $180 \mathrm{~g} / \mathrm{L}$ of sugars). The different Brix values were used due to the fact that cheese whey concentration is variable according to the industry in which it is generated. Thus, this assay allowed the verification of the yeast's ability to ferment cheese whey from different industries. Four isolates, T. delbrueckii B14, B20 and B35 and K. lactis B10 showed higher reductions in the Brix value at the end of fermentation independent of the initial Brix (Fig. 2). These 4 yeast isolates were submitted to molecular identification by sequencing the ITS region. The sequences were deposited in NCBI under accession numbers KY203860 (B10), KY203861 (B14), KY203862 (B20) and KY203863 (B35) (Table 2). Based on the sequencing, the isolates B14, B20 and B35 were identified as T. delbrueckii with similarity ranging from $96 \%$ to $99 \%$ when compared to the Genbank sequences used as reference (Table 2). The isolate B10 was identified as $K$. lactis with $96 \%$ of similarity compared to the reference sequence KP219449.1 (Table 2). The identification obtained by ITS region sequencing confirmed the identification by MALDI TOF reinforcing the feasibility of this last technique uses for yeast identification in fermentative processes.

The yeast $K$. lactis B10 showed the largest decreases in Brix degree, which were 7.3, 4.6 and 5.4 for the initial Brix 18, 14 and 12, respectively. Among T. delbrueckii isolates, the most efficient was B14 with Brix reductions of 6.8, 4.4 and 5.2, respectively for initial Brix of 18, 14 and 12. The largest reductions in Brix presented by K. lactis B10 and $T$. delbrueckii B14 may be due to the more efficient use of monosaccharides (glucose and galactose) present in cheese whey and the higher hydrolysis of lactose. Borelli et al. (2006) reported that among 25 studied isolates of $T$. delbrueckii, 2 were $\beta$-galactosidase producers, the enzyme responsible for the breakdown of lactose into glucose and galactose, monosaccharides fermented by this yeast. All three evaluated $T$. delbrueckii isolates showed the capacity to grow in YNB with lactose as sole carbon source, which indicates their ability to produce $\beta$ galactosidase.

Since the yeast $K$. lactis is part of the $2 \%$ of known yeasts species capable of fermenting lactose (Aktaş, Boyaci, Mutlu, \& Tanyolaç, 2006; Fonseca, Heinzle, Wittmann, \& Gombert, 2008) several authors have

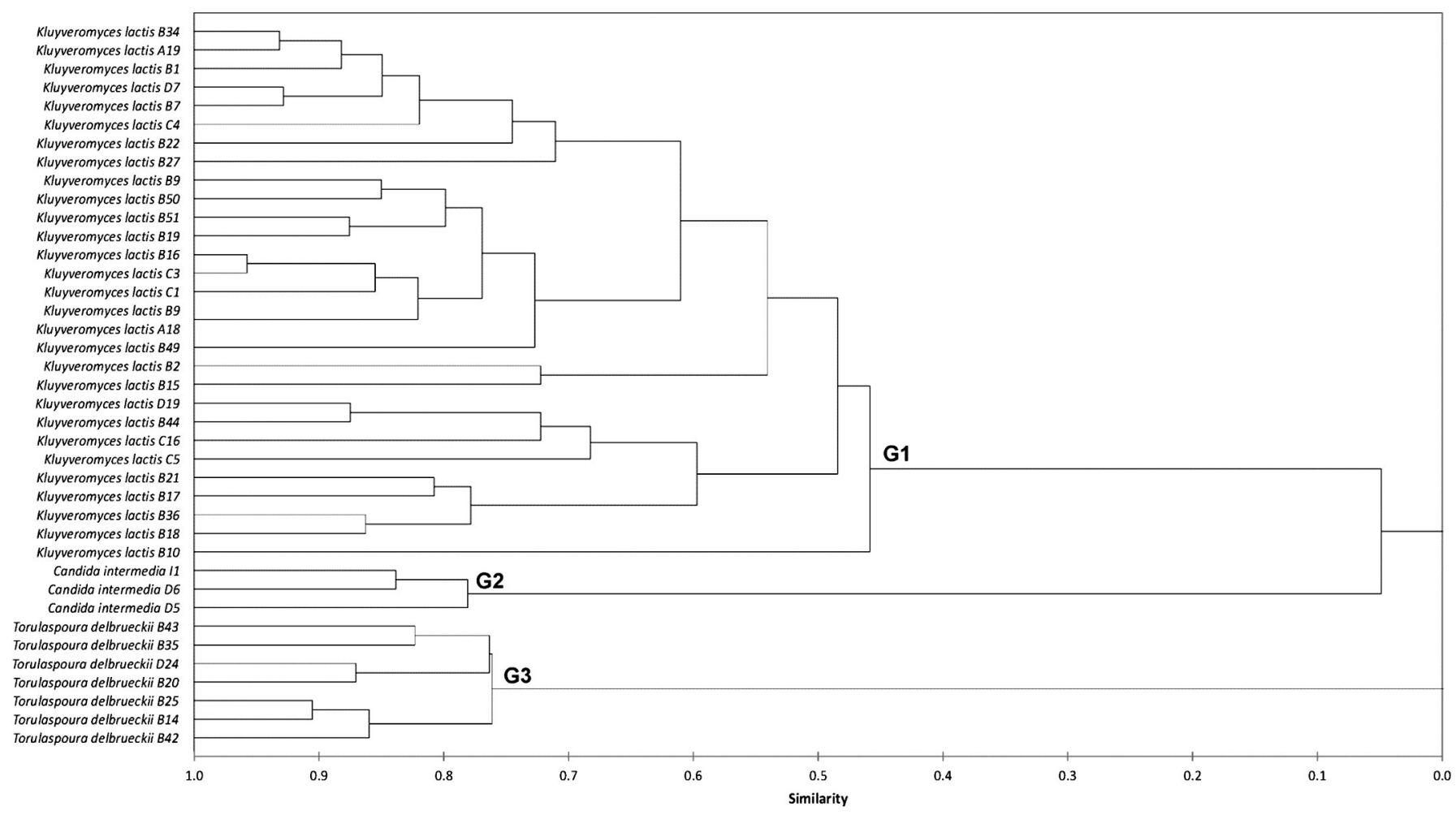

Fig. 1. Dendrogram of protein profile of 39 yeasts isolates that ferment lactose in synthetic medium. 


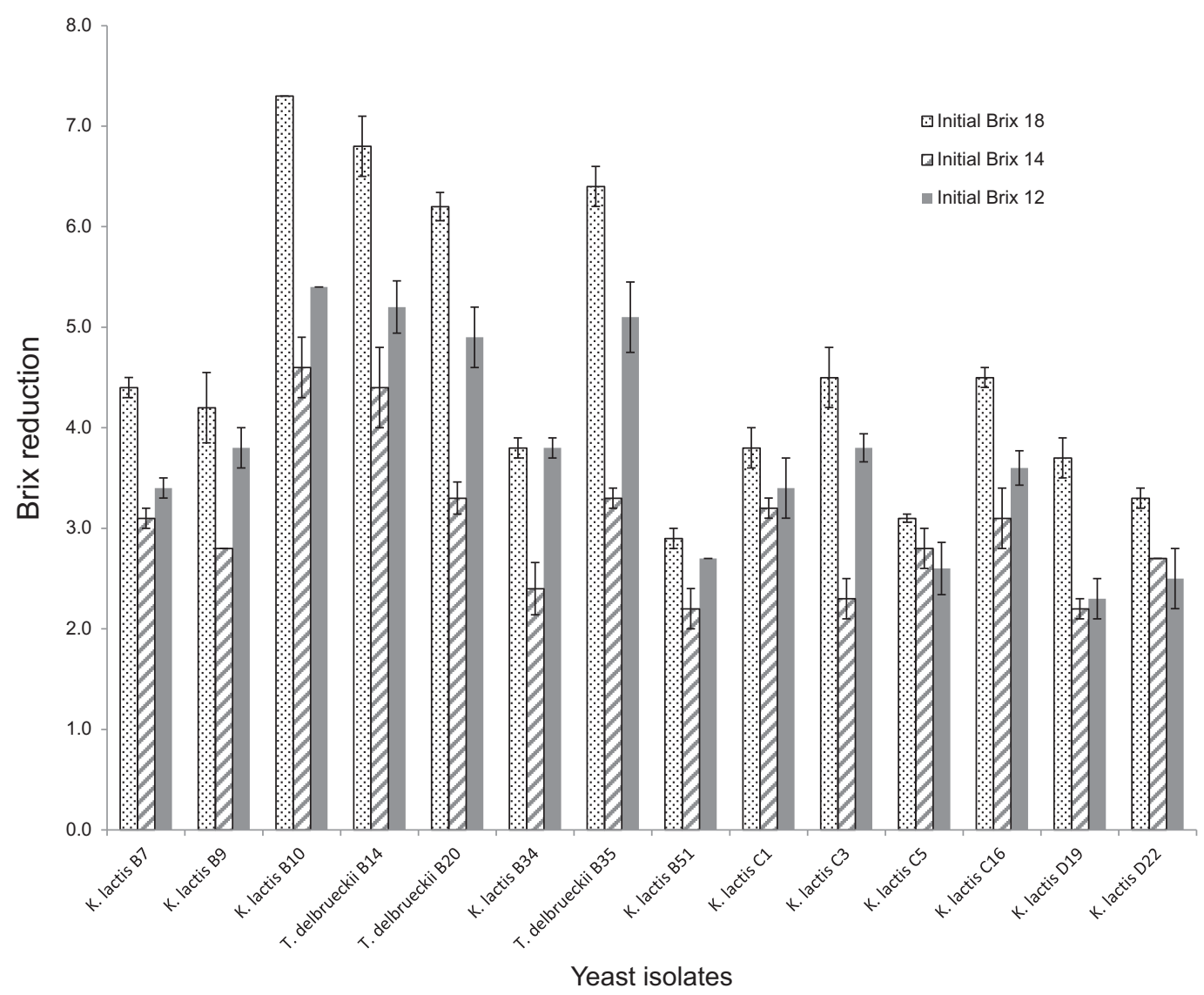

Fig. 2. Profile of sugars consumption (Brix) by different yeasts fermenting cheese whey with three different initial Brix.

isolated this cheese yeast and evaluated its potential for fermentation of lactose and enzyme production (Borelli et al., 2006; Lima et al., 2009; Nóbrega et al., 2008; Padilla, Manzanares, \& Belloch, 2014). Although, in general, intermediate reductions was observed for initial 14 Brix, this initial Brix was considered for the fermentations in the next stages of work due to the fact that the cheese whey samples from the supplier industry always presented Brix around 14 .

\subsection{Evaluation of single and mixed inocula for cheese whey fermentation and ethanol production}

Initially, the fermentation was carried out with each yeast (K. lactis B10 and T. delbrueckii B14) inoculated individually for evaluation of sugars consumption and ethanol production (Table 3). The total sugars consumption by K. lactis B10 was $98.38 \mathrm{~g} / \mathrm{L}$, being $23.33 \mathrm{~g} / \mathrm{L}$ of lactose, $56.45 \mathrm{~g} / \mathrm{L}$ of glucose and $18.60 \mathrm{~g} / \mathrm{L}$ galactose, corresponding to a total conversion of sugars (Conv) of 59.22\%, ethanol production efficiency (Ef) of $25.92 \%$ and $\mathrm{Y}_{\mathrm{p} / \mathrm{s}} 0.13 \mathrm{~g} / \mathrm{g}$ (Table 3). Although K. lactis B10 has consumed more lactose compared to the other yeast, probably due to its capacity to produce $\beta$-galactosidase, this yeast did not show greater

Table 2

Yeast species identification by MALDI TOF and ITS region sequencing.

\begin{tabular}{lllll}
\hline Isolates & Identification & $\begin{array}{l}\text { Reference } \\
\text { sequence GenBank }\end{array}$ & $\begin{array}{l}\text { Genbank } \\
\text { accession number }\end{array}$ \\
\cline { 2 - 3 } & MALDI TOF & ITS region & KP219449.1 & KY203860 \\
\hline B10 & K. lactis & K. lactis & KY203861 \\
B14 & T. delbrueckii & T. delbrueckii & KU296045.1 & KY203862 \\
B20 & T. delbrueckii & T. delbrueckii & KF300898.1 & KY203863 \\
B35 & T. delbrueckii & T. delbrueckii & KU296045.1 & KY203863 \\
\hline
\end{tabular}

efficiency in ethanol production (Table 3). The highest ethanol production, $24.06 \mathrm{~g} / \mathrm{L}$, was observed for T. delbrueckii B14 (Table 3). This yeast showed a total sugar consumption of $108.25 \mathrm{~g} / \mathrm{L}$ being glucose and galactose the main consumed sugars (Table 3). Furthermore, this strain showed Conv. value of $65.12 \%, E f$ of $43.58 \%$ and $\mathrm{Y}_{\mathrm{p} / \mathrm{s}}$ of $0.22 \mathrm{~g} / \mathrm{g}$ (Table 3). T. delbrueckii B35 have shown the same values of $Y_{p / s}(0.22 \mathrm{~g} / \mathrm{g})$, similar values for ethanol concentration and Conv., however, the total sugar consumption $(73.81 \mathrm{~g} / \mathrm{L})$ presented by this yeast was significantly lower than that observed for T. delbrueckii B14.

Taking into account that $K$. lactis B10 was more efficient in the consumption of lactose and the fact that the T. delbrueckii B14 showed the highest efficiency in ethanol production and consumption of monosaccharides, both yeasts were selected to be used as mixed inoculum, aiming to optimize the sugar's consumption and ethanol production. In Mix 1, K. lactis B10 and T. delbrueckii B14 were inoculated together at the beginning of fermentation; Mix 2 was a sequential inoculation of $K$. lactis B10 after 48 h of fermentation with T. delbrueckii B14; Mix 3, T. delbrueckii B14 was inoculated $48 \mathrm{~h}$ after K. lactis B10.

As can be seen in Table 4 , after $48 \mathrm{~h}$ of fermentation with the mixed inoculum of two yeasts, ethanol production was $21.52 \mathrm{~g} / \mathrm{L}$, with glucose being completely consumed, while the residual concentration of galactose was $0.48 \mathrm{~g} / \mathrm{L}$. However, only after $144 \mathrm{~h}$ of fermentation there was significant reduction in lactose content, resulting in total sugars consumption of $106.69 \mathrm{~g} / \mathrm{L}$ corresponding to a Conv. of $92.29 \%$, Ef of $38.61 \%$ and $Y_{p / s} 0.21 \mathrm{~g} / \mathrm{g}$ (Table 4 ). The highest total sugars consumption $(113.08 \mathrm{~g} / \mathrm{L})$ was obtained after $144 \mathrm{~h}$ of fermentation when K. lactis B10 was inoculated $48 \mathrm{~h}$ after T. delbrueckii B14 inoculation (Mix 2), resulting in a Conv. of $97.82 \%, \mathrm{Y}_{\mathrm{p} / \mathrm{s}} 0.18 \mathrm{~g} / \mathrm{g}$ and ethanol concentration of $19.81 \mathrm{~g} / \mathrm{L}$ ethanol (Table 4). The $E f$ and $\mathrm{Y}_{\mathrm{p} / \mathrm{s}}$ values found for Mix 1 and Mix 2 after $144 \mathrm{~h}$ of fermentation were intermediate values when compared with those obtained for single inocula of T. delbrueckii B14 and $K$. lactis B10 (Table 3). However, the total sugar conversion 
Table 3

Concentration of sugars and ethanol $(\mathrm{g} / \mathrm{L})$ and kinetic parameters for fermentation with yeasts pure cultures.

\begin{tabular}{|c|c|c|c|c|c|c|c|c|}
\hline Samples & Lactose & Glucose & Galactose & Ethanol & Sugars consumption & $\begin{array}{l}Y_{\mathrm{p} / \mathrm{s}} \\
\mathrm{g} / \mathrm{g}\end{array}$ & $E f(\%)$ & Conv. (\%) \\
\hline Cheese whey & $60.92 \pm 0.81$ & $60.29 \pm 0.80$ & $44.91 \pm 0.17$ & nd & - & - & - & - \\
\hline Torulaspora delbrueckii (B14) & $52.87^{\mathrm{b}} \pm 0.25$ & nd & $5.00^{\mathrm{a}} \pm 0.23$ & $24.06^{\mathrm{a}} \pm 0.01$ & 108.25 & 0.22 & 43.58 & 65.16 \\
\hline Kluyveromyces lactis (B10) & $37.59^{a} \pm 3.59$ & $3.84^{\mathrm{a}} \pm 4.51$ & $26.31^{\mathrm{b}} \pm 2.28$ & $13.01^{\mathrm{a}} \pm 1.15$ & 98.39 & 0.13 & 25.92 & 59.23 \\
\hline Torulaspora delbrueckii (B20) & $48.11^{\mathrm{b}} \pm 0.02$ & $3.62^{\mathrm{a}} \pm 0.01$ & $28.98^{\mathrm{b}} \pm 0.04$ & $12.86^{\mathrm{a}} \pm 0.02$ & 85.41 & 0.15 & 29.51 & 51.41 \\
\hline Torulaspora delbrueckii (B35) & $50.42^{\mathrm{b}} \pm 2.73$ & $10.71^{\mathrm{a}} \pm 3.51$ & $31.18^{\mathrm{b}} \pm 4.34$ & $16.45^{\mathrm{a}} \pm 3.11$ & 73.81 & 0.22 & 43.71 & 44.43 \\
\hline
\end{tabular}

nd - not detected. Values identified by the same letters are not significantly different at the 0.05 level (Scott-Knott test).

(Conv.) was significantly increased due to the consumption of lactose mainly for the Mix 2. The concentration of ethanol and $Y_{p / s}$ found in this study differ from those reported in the literature, being lower than those reported by Dragone, Mussatto, de Almeida, and Teixeira (2011) or higher than those reported by Ozmihci and Kargi (2008). These differences between the values found here and those reported in the literature can be attributed to cheese whey composition and also to the used yeasts. Although the Mix 1 and Mix 2 have resulted in a similar ethanol concentration after $144 \mathrm{~h}$ of fermentation, the total sugar consumption, especially lactose consumption, was higher for Mix 2. This mix was established as best option for cheese whey fermentation to produce ethanol and to be evaluated for the production of volatile aromatic compounds.

3.4. Cheese whey fermentation with selected inoculum for ethanol and aromatic volatile compounds production

Sequential inoculation of $K$. lactis B10 after $48 \mathrm{~h}$ of fermentation with T. delbrueckii B14 (Mix 2) was repeated fermenting 1 L of 14 Brix cheese whey. The obtained results were similar to those reported previously, being $\mathrm{Y}_{\mathrm{p} / \mathrm{s}} 0.14 \mathrm{~g} / \mathrm{g}$ and $E f$ of $27.41 \%$. The differences found between the first and second fermentation can be attributed to the increase in volume of fermented cheese whey, indicating the need for further studies to evaluate other parameters during the fermentation as those reported by Zoppellari and Bardi (2013) including available oxygen and temperature.

The fermentation process generates, in addition to ethanol, a large number of other metabolites such as higher alcohols, esters, acids, ketones and others which can influence the quality of the final product. In this study, 39 aromatic volatile compounds were identified, being 9 acids, 13 alcohols, 13 esters and 4 other compounds (Table 5). The 3methyl-1-butanol, 2-methyl-1-butanol and 2-phenyl ethanol were the most abundant alcohols being found in concentrations of $123.59 \mu \mathrm{g} / \mathrm{L}$, $52.72 \mu \mathrm{g} / \mathrm{L}$ and $77.11 \mu \mathrm{g} / \mathrm{L}$, respectively. In cheeses, 3-methyl-1-butanol is considered a major contributor to the overall flavor of the product. According to Nogueira, Lubachevsky, and Rankin (2005), this compound develops important role in the flavor of Minas cheese. This alcohol is frequently associated with good sensorial descriptors such as "sweet and fresh". 2-Methyl-1-butanol is associated with descriptors such as "alcoholic, green and pomace", while 2-phenylethanol odor is described as "floral" (Curioni \& Bosset, 2002). In addition to the presence and importance to cheeses, the alcohols mentioned above were reported by Dragone, Mussatto, Oliveira, and Teixeira (2009) as the main alcohols found in an alcoholic beverage produced from the fermentation of cheese whey.

Hexanoic, octanoic and decanoic were found in concentrations of $107.92 \mu \mathrm{g} / \mathrm{L}, 173.04 \mu \mathrm{g} / \mathrm{L}, 51.58 \mu \mathrm{g} / \mathrm{L}$, respectively (Table 5). These three acids together with butanoic acid are frequently reported as presented in cheeses. Moio, Piombino, and Addeo (2000) found that these acids represented approximately $80 \%$ of the volatile acid fraction in Gorgonzola cheese. The hexanoic acid and butanoic acid are considered responsible for a "strong and spicy" flavor in cheese (Moio \& Addeo, 1998), which may be desirable or not, depending on the type of cheese. The aromatic descriptors of octanoic and decanoic acids are "unpleasant, fatty and rancid" (Curioni \& Bosset, 2002).

Production of fatty acids in dairy products may be associated with metabolites generated through lactose metabolism by deamination of amino acids and also by lipid oxidation (Hayaloglu, Brechany, Deegan, \& McSweeney, 2008; Nogueira et al., 2005).

Thirteen esters were identified, with a total concentration of $292.09 \mu \mathrm{g} / \mathrm{L}$. Among them, ethyl decanoate, and 9-ethyl decenoate were found with concentrations of $175.22 \mu \mathrm{g} / \mathrm{L}$ and $62.16 \mu \mathrm{g} / \mathrm{L}$, respectively (Table 5). Due to their volatility at room temperature, the esters significantly contribute to the taste of many cheeses, even at low concentrations. Besides being associated with descriptors such as "fruity and floral", these compounds may further reduce the perception of the unpleasant smell of some free fatty acids (Nogueira et al., 2005).

The variety and concentrations of the compounds found in this work indicate that the used yeasts may have potential for use as inoculum in cheese making process during the fermentation or maturation giving improvements in cheese sensory characteristics.

\section{Conclusions}

From a total of 145 isolates, K. lactis B10 and T. delbrueckii B14, showed better efficiency in fermenting cheese whey when used

Table 4

Concentration of sugars and ethanol $(\mathrm{g} / \mathrm{L})$ and kinetic parameters for fermentation with mixed inocula.

\begin{tabular}{|c|c|c|c|c|c|c|c|c|}
\hline Samples & Lactose & Glucose & Galactose & Ethanol & Sugars consumption & $\begin{array}{l}Y_{p / s} \\
g / g\end{array}$ & $E f(\%)$ & Conv. (\%) \\
\hline Mix $148 \mathrm{~h}$ & $29.19^{c} \pm 0.02$ & nd & $0.48^{\mathrm{a}} \pm 0.08$ & $21.52 b \pm 0.10$ & 85.93 & 0.25 & 49.11 & 74.33 \\
\hline Mix $172 \mathrm{~h}$ & $22.44^{\mathrm{c}} \pm 0.90$ & nd & $1.84^{\mathrm{a}} \pm 0.63$ & $18.86^{\mathrm{b}} \pm 2.90$ & 91.32 & 0.20 & 40.50 & 79.00 \\
\hline Mix $1144 \mathrm{~h}$ & $6.22^{\mathrm{b}} \pm 3.88$ & nd & $2.68^{a} \pm 0.79$ & $21.00^{\mathrm{b}} \pm 0.01$ & 106.69 & 0.21 & 38.61 & 92.29 \\
\hline Mix $248 \mathrm{~h}$ & $36.36^{\mathrm{d}} \pm 1.43$ & nd & $0.67^{\mathrm{a}} \pm 3.61$ & $21.25^{\mathrm{b}} \pm 4.71$ & 78.56 & 0.27 & 53.04 & 67.96 \\
\hline Mix $272 \mathrm{~h}$ & $1.95^{\mathrm{a}} \pm 0.68$ & nd & $1.34^{\mathrm{a}} \pm 0.63$ & $19.71^{\mathrm{b}} \pm 2.82$ & 112.31 & 0.18 & 34.41 & 97.15 \\
\hline Mix $2144 \mathrm{~h}$ & nd & $0.24^{\mathrm{a}} \pm 1.30$ & $2.28^{\mathrm{a}} \pm 0.47$ & $19.81^{\mathrm{b}} \pm 1.02$ & 113.08 & 0.18 & 34.35 & 97.82 \\
\hline Mix 348 h & $41.62^{\mathrm{e}} \pm 0.08$ & $22.63^{b} \pm 3.97$ & $34.85^{b} \pm 0.69$ & $5.21^{\mathrm{a}} \pm 1.74$ & 59.44 & 0.09 & 17.17 & 37.49 \\
\hline Mix $372 \mathrm{~h}$ & $35.81^{\mathrm{d}} \pm 0.44$ & $4.21^{\mathrm{a}} \pm 3.29$ & $33.05^{\mathrm{b}} \pm 0.38$ & $6.02^{\mathrm{a}} \pm 0.47$ & 85.47 & 0.07 & 13.82 & 53.91 \\
\hline Mix $3144 \mathrm{~h}$ & $30.06^{c} \pm 0.34$ & $1.35 a \pm 2.28$ & $30.43^{\mathrm{b}} \pm 2.44$ & $9.60^{\mathrm{a}} \pm 1.53$ & 96.69 & 0.10 & 19.72 & 60.99 \\
\hline
\end{tabular}

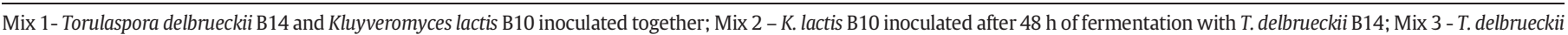
B14 inoculated after $48 \mathrm{~h}$ of fermentation with K. lactis B10. nd - not detected. Values identified by the same letters are not significantly different at the 0.05 level (Scott-Knott test). 
Table 5

Volatile compounds concentration ( $\mu \mathrm{g} / \mathrm{L}$ ) by GC-MS in fermented cheese whey.

\begin{tabular}{|c|c|c|}
\hline $\mathrm{N}^{\circ}$ & Compounds & Concentration \\
\hline & Acids & \\
\hline 1 & 3-Decenoic acid & $0.57 \pm 0.00$ \\
\hline 2 & 2-Methyl butyric acid* & $9.05 \pm 1.80$ \\
\hline 3 & Hexanoic acid* & $107.92 \pm 0.93$ \\
\hline 4 & 2-Ethyl caproic acid* & $0.97 \pm 0.06$ \\
\hline 5 & Heptanoic acid** & $1.48 \pm 0.60$ \\
\hline 6 & Octanoic acid* & $173.04 \pm 47.74$ \\
\hline 7 & Nonanoic acid* & $1.23 \pm 0.53$ \\
\hline 8 & n-Decanoic acid** & $51.58 \pm 10.63$ \\
\hline \multirow[t]{3}{*}{9} & Benzoic acid* & $36.58 \pm 9.12$ \\
\hline & Total & 382.44 \\
\hline & Alcohols & \\
\hline 10 & 2-Methyl-1-butanol* & $52.72 \pm 47.00$ \\
\hline 11 & 3-Methyl-1-butanol* & $123.59 \pm 14.52$ \\
\hline 12 & 2-Hexadecanol** & $6.96 \pm 2.26$ \\
\hline 13 & 2-Heptanol* & $1.32 \pm 0.41$ \\
\hline 14 & 2-Ethyl-1-hexanol** & $7.90 \pm 0.59$ \\
\hline 15 & 2-Decanol** & $10.46 \pm 0.91$ \\
\hline 16 & 3-Methyl-2-octanol** & $0.28 \pm 0.39$ \\
\hline 17 & 2,3-Butanodiol** & $8.59 \pm 0.71$ \\
\hline 18 & 5-Ethyl-2-heptanol** & $0.23 \pm 0.33$ \\
\hline 19 & 1-Decanol** & $1.74 \pm 0.22$ \\
\hline 20 & 2-Phenylethanol* & $77.11 \pm 13.42$ \\
\hline 21 & 2-Octanol** & $3.97 \pm 1.50$ \\
\hline \multirow[t]{3}{*}{22} & 3-Methyl-2-butanol** & $2.51 \pm 1.12$ \\
\hline & Total & 297.39 \\
\hline & Esters & \\
\hline 23 & Ethyl nonanoate** & $7.17 \pm 3.41$ \\
\hline 24 & Ethyl 2-hydroxy-4-methylpentanoate ${ }^{* *}$ & $1.94 \pm 0.81$ \\
\hline 25 & Ethyl decanoate* & $175.22 \pm 37.73$ \\
\hline 26 & Isoamyl octanoate* & $0.66 \pm 0.31$ \\
\hline 27 & Ethyl 9-decenoate** & $62.16 \pm 10.83$ \\
\hline 28 & Ethyl dodecanoate** & $7.58 \pm 1.31$ \\
\hline 29 & Ethyl hexadecanoate** & $1.38 \pm 0.01$ \\
\hline 30 & Isobornyl acetate** & $2.33 \pm 0.45$ \\
\hline 31 & Isoamyl lactate* & $12.86 \pm 1.71$ \\
\hline 32 & Ethyl iso-allocholate** & $0.36 \pm 0.10$ \\
\hline 33 & cis-3-Decenyl acetate** & $1.64 \pm 0.41$ \\
\hline 34 & 2-Phenethyl acetate* & $18.66 \pm 2.74$ \\
\hline \multirow[t]{3}{*}{35} & trans-9-Tetradecen-1-yl acetate** & $0.13 \pm 0.03$ \\
\hline & Total & 292.09 \\
\hline & Others & \\
\hline 36 & Acetoin* & $6.96 \pm 2.26$ \\
\hline 37 & Ethylpyrazine* & $0.70 \pm 0.34$ \\
\hline 38 & Isoborneol $^{* *}$ & $0.40 \pm 0.08$ \\
\hline \multirow[t]{2}{*}{39} & Alfa-bisabolol & $0.10 \pm 0.14$ \\
\hline & Total & 8.15 \\
\hline
\end{tabular}

Identification based on *pure standards or **NIST library.

sequentially with $K$. lactis B10 inoculated after 48 h of fermentation with T. delbrueckii B14. This mixed inoculum showed potential to produce ethanol from cheese whey sugars, especially lactose, indicating a possible use of this by-product for the production of biofuel. Also, the conversion of cheese whey sugars into aromatic volatile compounds, especially alcohols and esters responsible for pleasant aromas and flavors in cheese, demonstrate that the yeast K. lactis B10 and T. delbrueckii B14 can be evaluated in the production of cheeses aiming improvements in the sensory characteristics of the final product. Further studies should be performed to optimize the production of ethanol and to evaluate the use of the aforementioned yeast directly in the production of Canastra cheese.

\section{Acknowledgments}

The authors thank CNPq (Conselho Nacional de Desenvolvimento Científico e Tecnológico do Brasil), CAPES (Coordenação de Aperfeiçoamento de Pessoal de Nível Superior) and FAPEMIG (Fundação de Amparo à Pesquisa do Estado de Minas Gerais) for financial support. The authors also thank J.C Amorim for her help in MALDI TOF analysis and Dr. P.S Geraldino for her help in sequences analysis.

\section{References}

Addis, E., Fleet, G. H., Cox, J. M., Kolak, D., \& Leung, T. (2001). The growth, properties and interactions of yeasts and bacteria associated with the maturation of Camembert and blue-veined cheeses. International Journal of Food Microbiology, 69, 25-36.

Aktaş, N., Boyaci, I. H., Mutlu, M., \& Tanyolaç, A. (2006). Optimization of lactose utilization in deproteinated whey by Kluyveromyces marxianus using response surface methodology (RSM). Bioresource Technology, 97, 2252-2259.

Alm, R., Johansson, P., Hjernø, K., Emanuelsson, C., Ringnér, M., \& Häkkinen, J. (2006). Detection and identification of protein isoforms using cluster analysis of MALDI-MS mass spectra. Journal of Proteome Research, 5, 785-792.

Alves, M. P., Moreira, R., de, O., Júnior, P. H. R., Martins, M. C., de, F., ... De (2014). Whey: Technologies for coproducts production. Revista do Instituto de Laticínios Cândido Tostes, 69, 212-226.

Amorim, J. C., Schwan, R. F., \& Duarte, W. F. (2016). Sugar cane spirit (cachaça): Effects of mixed inoculum of yeasts on the sensory and chemical characteristics. Food Research International, 85, 76-83.

Becerra, M., Cerdán, M. E., \& González-Siso, M. I. (2015). Biobutanol from cheese whey. Microbial Cell Factories, 14, 27.

Borelli, B. M., Ferreira, E. G., Lacerda, I. C. A., Franco, G. R., \& Rosa, C. A. (2006). Yeast populations associated with the artisanal cheese produced in the region of Serra da Canastra, Brazil. World Journal of Microbiology and Biotechnology, 22, 1115-1119.

Cardoso, V. M., Borelli, B. M., Lara, C. A., Soares, M. A., Pataro, C., Bodevan, E. C., \& Rosa, C. A. (2015). The influence of seasons and ripening time on yeast communities of a traditional Brazilian cheese. Food Research International, 69, 331-340.

Chen, L., Shui, Cui, J., Ding, Q., Ma, B., Chen, Y., Jun, L., Dong, J., Ying, ... Maubois, ... Louis, J. (2012). The effect of yeast species from raw milk in China on proteolysis and aroma compound formation in Camembert-type cheese. Food and Bioprocess Technology, 5 , 2548-2556.

Christensen, A. D., Kádár, Z., Oleskowicz-Popiel, P., \& Thomsen, M. H. (2011). Production of bioethanol from organic whey using Kluyveromyces marxianus. Journal of Industrial Microbiology and Biotechnology, 38, 283-289.

Cota-Navarro, C. B., Carrillo-Reyes, J., Davila-Vazquez, G., Alatriste-Mondragón, F., \& RazoFlores, E. (2011). Continuous hydrogen and methane production in a two-stage cheese whey fermentation system. Water Science and Technology, 64, 367-374.

Curioni, P. M. G., \& Bosset, J. O. (2002). Key odorants in various cheese types as determined by gas chromatography-olfactometry. International Dairy Journal, 12, 959-984.

Dragone, G., Mussatto, S. I., Oliveira, J. M., \& Teixeira, J. A. (2009). Characterisation of volatile compounds in an alcoholic beverage produced by whey fermentation. Food Chemistry, 112, 929-935.

Dragone, G., Mussatto, S. I., Almeida de Silva, J. B., \& Teixeira, J. A. (2011). Optimal fermentation conditions for maximizing the ethanol production by Kluyveromyces fragilis from cheese whey powder. Biomass and Bioenergy, 35, 1977-1982.

Duarte, W. F., Dragone, G., Dias, D. R., Oliveira, J. M., Teixeira, J. A., Silva, J. B. A. E., \& Schwan, R. F. (2010a). Fermentative behavior of Saccharomyces strains during microvinification of raspberry juice (Rubus idaeus L.). International Journal of Food Microbiology, 143, 173-182.

Duarte, W. F., Dias, D. R., Oliveira, J. M., Vilanova, M., Teixeira, J. A., de Silva, J. B. A., \& Schwan, R. F. (2010b). Raspberry (Rubus idaeus L.) wine: Yeast selection, sensory evaluation and instrumental analysis of volatile and other compounds. Food Research International, 43, 2303-2314.

Esteve-Zarzoso, B., Belloch, C., Uruburu, F., \& Querol, A. (1999). Identification of yeasts by RFLP analysis of the 5.8S rRNA gene and the two ribosomal internal transcribed spacers. International Journal of Systematic Bacteriology, 49(Pt 1), 329-337.

Fonseca, G. G., Heinzle, E., Wittmann, C., \& Gombert, A. K. (2008). The yeast Kluyveromyces marxianus and its biotechnological potential. Applied Microbiology and Biotechnology, 79, 339-354.

Gardini, F., Tofalo, R., Belletti, N., Iucci, L., Suzzi, G., Torriani, S., ... Lanciotti, R. (2006). Characterization of yeasts involved in the ripening of Pecorino Crotonese cheese. Food Microbiology, 23, 641-648.

Hayaloglu, A. A., Brechany, E. Y., Deegan, K. C., \& McSweeney, P. L. H. (2008). Characterization of the chemistry, biochemistry and volatile profile of Kuflu cheese, a mouldripened variety. LWT - Food Science and Technology, 41, 1323-1334.

Jakobsen, M., \& Narvhus, J. (1996). Yeasts and their possible beneficial and negative effects on the quality of dairy products. International Dairy Journal, 6, 755-768.

Kurtzman, C. P., Fell, J. W., Boekhout, T., \& Robert, V. (2011). Chapter 7 - Methods for isolation, phenotypic characterization and maintenance of yeasts BT - the yeasts (fifth edition). CHAP, London: Elsevier, 87-110.

Lima, C. D. L. C., Lima, L. A., Cerqueira, M. M. O. P., Ferreira, E. G., \& Rosa, C. A. (2009). Bactérias do acido láctico e leveduras associadas com o queijo-de-minas artesanal produzido na região da Serra do Salitre, Minas Gerais. Arquivo Brasileiro de Medicina Veterinaria E Zootecnia, 61, 266-272.

Lopandic, K., Zelger, S., Bánszky, L. K., Eliskases-Lechner, F., \& Prillinger, H. (2006). Identification of yeasts associated with milk products using traditional and molecular techniques. Food Microbiology, 23, 341-350.

Moio, L., \& Addeo, F. (1998). Grana Padano cheese aroma. Journal of Dairy Research, 65 317-333.

Moio, L., Piombino, P., \& Addeo, F. (2000). Odour-impact compounds of Gorgonzola cheese. The Journal of Dairy Research, 67, 273-285.

Moothoo-Padayachie, A., Kandappa, H. R., Krishna, S. B. N., Maier, T., \& Govender, P. (2013). Biotyping Saccharomyces cerevisiae strains using matrix-assisted laser 
desorption/ionization time-of-flight mass spectrometry (MALDI-TOF MS). European Food Research and Technology, 236, 351-364.

Naumova, E. S., Ivannikova, Y. V., \& Naumov, G. I. (2005). Genetic differentiation of the sherry yeasts Saccharomyces cerevisiae. Applied Biochemistry and Microbiology, 41, 578-582.

Niedermeyer, T. H. J., \& Strohalm, M. (2012). Mass as a software tool for the annotation of cyclic peptide tandem mass spectra. PloS One, 7, e44913.

Nóbrega, J. E., Ferreira, C., Dores, M., Ferreira, E., Domingo, E., \& Santos, J. (2008). Variaç̃es na microbiota leveduriforme do fermento endógeno utilizado na produção do queijo Canastra. Revista do Instituto de Laticínio Candido Tostes, 364, 14-18.

Nogueira, M. C. L., Lubachevsky, G., \& Rankin, S. A. (2005). A study of the volatile composition of Minas cheese. LWT - Food Science and Technology, 38, 555-563.

Oliveira, E. S., Rosa, C. A., Morgano, M. A., \& Serra, G. E. (2004). Fermentation characteristics as criteria for selection of cachaça yeast. World Journal of Microbiology and Biotechnology, 20, 19-24.

Ozmihci, S., \& Kargi, F. (2008). Ethanol production from cheese whey powder solution in a packed column bioreactor at different hydraulic residence times. Biochemical Engineering Journal, 42, 180-185.

Padilla, B., Manzanares, P., \& Belloch, C. (2014). Yeast species and genetic heterogeneity within Debaryomyces hansenii along the ripening process of traditional ewes' and goats' cheeses. Food Microbiology, 38, 160-166.

Pereira-Dias, S., Potes, M. E., Marinho, A., Malfeito-Ferreira, M., \& Loureiro, V. (2000). Characterisation of yeast flora isolated from an artisanal Portuguese ewes' cheese. International Journal of Food Microbiology, 60, 55-63.
Rech, R., Cassini, C. F., Secchi, A., \& Ayub, M. A. Z. (1999). Utilization of protein-hydrolyzed cheese whey for production of $\beta$-galactosidase by Kluyveromyces marxianus. Journal of Industrial Microbiology and Biotechnology, 23, 91-96.

Resende, M., Costa, H., Andrade, E., Acúrcio, L., Drummond, A. F., Cunha, A. F., ... Souza, M. R. (2011). Influence of altitute on the lactic acid bacteria of Minas artisanal cheese from Serra da Canastra. Arquivo Brasileiro de Medicina Veterinária e Zootecnia, 63, 1567-1573.

Schirru, S. Favaro, L. Mangia, N. P. Basaglia, M Casella, S., Comunian, R Todorov, S. D. (2014). Comparison of bacteriocins production from Enterococcus faecium strains in cheese whey and optimised commercial MRS medium. Annals of Microbiology, 64, 321-331.

Spitaels, F., Wieme, A. D., Janssens, M., Aerts, M., Daniel, H. M., Van Landschoot, A., ... Vandamme, P. (2014). The microbial diversity of traditional spontaneously fermented lambic beer. PloS One, 9(4), e95384.

Urit, T., Löser, C. Wunderlich, M., \& Bley, T. (2011). Formation of ethyl acetate by Kluyveromyces marxianus on whey: Studies of the ester stripping. Bioprocess and Biosystems Engineering, 34, 547-559.

Usbeck, J., Wilde, C., Bertrand, D., Behr, J., \& Vogel, R. (2014). Wine yeast typing by MALDITOF MS. Applied Microbiology and Biotechnology, 98, 3737-3752.

Zoppellari, F., \& Bardi, L. (2013). Production of bioethanol from effluents of the dairy industry by Kluyveromyces marxianus. New Biotechnology, 30, 607-613. 